\title{
El gasto público ambiental de la provincia de Buenos Aires, Argentina (1997-2012)
}

Public environmental expenditure in the province of Buenos Aires, Argentina (1997-2012)

\author{
Verónica L. Cáceres \\ Universidad Nacional de General Sarmiento, Argentina. \\ vcaceres@ungs.edu.ar
}

doi:http://dx.doi.org/10.15359/abra.34-49.4

\begin{abstract}
Resumen: El artículo contribuye al debate sobre la cuestión ambiental en la provincia de Buenos Aires, particularmente, centra la atención en el análisis del gasto público ambiental durante 1997-2012. Considera que la estimación del gasto, la identificación de los actores que lo ejecutan y los programas que se implementan permiten tener una referencia de la relevancia que adquiere la cuestión en la agenda provincial. El trabajo se realizó a partir de la información presupuestaria producida por la Contaduría General de la provincia de Buenos Aires (PBA) dependiente del Ministerio de Economía mediante los clasificadores que utiliza la provincia. En primer lugar presenta la estimación y evolución del gasto ambiental de acuerdo con la clasificación provincial y luego se amplía con la clasificación de actividades y gastos de protección del medio ambiente (CAPA). En segundo, se caracteriza a los actores estatales que ejecutaron el gasto ambiental y el tipo de programas financiados; por último se presentan algunas conclusiones preliminares. El aporte central refiere a que el gasto público ambiental, luego de transcurrido una década de crecimiento, tras la crisis política, social y económica de 2001, no logró los niveles de participación de la convertibilidad. Asimismo, enfatiza en la ingeniería de agua y saneamiento, el cual tiene un fuerte componente de participación de las agencias centralizadas en detrimento de las que aglutinan las funciones ambientales principales, no se observan instancias de participación de la sociedad civil en su ejecución; y otorga escasa relevancia a las actividades de promoción y educación en materia ambiental.
\end{abstract}

Palabras claves: clasificadores; agencias estatales; programas ambientales

Abstract: This article contributes to the discussion on environmental issues in the province of Buenos Aires (PBA); particularly, it focuses on the analysis of public environmental expenditure during 1997-2012. It is considered that the estimation of the expenditure, the identification of the actors that implemented expenditure and the programs that are implemented indicate how relevant this issue is in the province's agenda.

The paper was based on the budget information prepared by PBA's General Accounting, which is dependant on the Ministry of Economy, through the classifiers used by the province. Firstly, the paper presents the estimation and evolution of environmental expenses according to the province classification and it is later broadened with the Classification of Environmental Protection Activities and Expenditure (CEPA 2000). Secondly, it identifies the state actors that implemented the environmental expense and the type of financed programs. Finally, some preliminary conclusions are presented. The

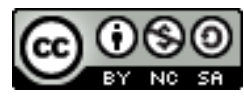

Esta obra está bajo licencia 
main contribution is that, after a decade of growth and after the political, social and economic crisis in 2001, the public environmental expenditure did not reach convertibility levels. In addition, the paper emphasizes water and sanitation engineering, which has a strong participation from centralized agencies in detriment to those that unify the main environmental functions. No instances of civil participation are observed in the execution and low relevance is given to environmental promotion and education activities.

Keywords: Classifiers; State agencies; Environmental programs

Fecha de recepción: 11-05-2014 Fechas de reenvíos: 03-09-2014/24-09-2014

Fecha de aceptación: 03-11-2014 Fecha de publicación: 20-11-2014

A partir de la década del 70 del siglo XX, la cuestión ambiental ha ganado espacio en la agenda internacional y ha dado lugar al desarrollo de cumbres internacionales, la firma de tratados y la instalación del paradigma del desarrollo sostenible. En este marco también han cobrado importancia las metodologías que clasifican el gasto público ambiental efectuado por los organismos estatales y el gasto ambiental privado destinado por las empresas y hogares, en ambos casos para prevenir, mitigar o reducir las emisiones de contaminantes, restaurar los daños causados al ambiente, proteger y/o conservar los ecosistemas así como al desarrollo de infraestructura ambiental y el consumo de energías renovables (Quadri de la Torre, 2002). Las metodologías de medición han contado con el impulso de las intervenciones de la Organización de Cooperación y Desarrollo Económico, la Organización de Naciones Unidas y la Unión Europea.

Distintas investigaciones han avanzado en la cuantificación e identificación del gasto público ambiental realizado por los Estados Nacionales de la región, como Perú, Argentina, Costa Rica, entre otros, pero no se ha avanzado en el análisis del gasto efectuado por los niveles subnacionales. El presente artículo se propone contribuir al debate en torno al gasto público ambiental efectuado por la provincia de Buenos Aires (PBA), Argentina durante 1997-2012. Asimismo, se considera que la estimación del gasto, la identificación de los actores que lo ejecutan y los programas que se implementan nos permite dar cuenta, en cierta forma, de la relevancia que adquiere la cuestión ambiental en la agenda provincial.

Cabe destacar que Argentina adopta constitucionalmente una forma federal de gobierno que reconoce la preexistencia de las provincias a la nación y por ello las provincias conservan las competencias no delegadas al gobierno federal. Las 23 provincias y la Ciudad Autónoma de Buenos Aires (CABA) conforman instancias autónomas que dictan sus propias constituciones y votan sus gobernantes. En materia ambiental, le corresponde a la nación la responsabilidad de "dictar las normas que contengan los presupuestos mínimos de protección" y a las provincias, que tienen "el dominio originario de los recursos naturales existentes en su territorio", complementarlos (artículos 41 y 124 de la Constitución Nacional) ${ }^{1}$. Por lo que, el nivel provincial asume un conjunto de funciones relevantes en materia ambiental que incluyen la preservación, recuperación y

${ }^{1}$ La Nación ejerce jurisdicción sobre la navegación, el comercio interprovincial e internacional, las relaciones internacionales, la celebración de tratados internacionales.

Verónica L. Cáceres

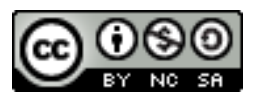

Esta obra está bajo licencia Creative Commons Reconocimiento-NoComercial-Compartirlgual 4.0 Internacional License 
conservación de los recursos naturales renovables y no renovables, el control del impacto ambiental, la planificación del uso racional de los recursos, la promoción de actividades que eviten la degradación del aire, de los recursos hídricos, de los suelos, entre otras. Más allá de lo cual, en Argentina, el gasto público ambiental ejecutado por el nivel subnacional ha sido escasamente explorado y particularmente sobre la PBA no se han encontrado antecedentes, por lo que el artículo asume un carácter exploratorio.

La PBA es el principal distrito del país y el desempeño de los principales indicadores económicos provinciales siguen muy de cerca la evolución de los indicadores nacionales. En 2010 contaba con una población total que ascendía a 15.625.084 habitantes (lo que representaba el 38,95 \% del país) que se distribuía de forma heterogénea en dos regiones geográficas diferenciadas con dinámica demográfica propia: por un lado, los partidos del Gran Buenos Aires o Conurbano Bonaerense integrado por 24 partidos que rodean a la CABA que concentraban al 63,46 \% de la población, y por otro, el Interior Provincial conformado por 111 partidos donde se localizaba el resto de la población (Instituto Nacional de Estadísticas y Censos, 2010).

En Argentina, el producto bruto geográfico (PBG) muestra la actividad económica de las unidades productivas que residen en las jurisdicciones provinciales que integran el país, y que, desde el punto de vista contable, resulta de la agregación de los saldos de la cuenta de producción de las distintas ramas de actividad. En 2013, el PBG de la PBA mostraba una estructura productiva diversificada donde la industria manufacturera alcanzaba al 27,9\%; los servicios de transporte 17,8 \%; los servicios inmobiliarios $14,9 \%$; el comercio 14,2 \%; la construcción al 5,6 \% y el sector primario solo al 4,4\%, pero con encadenamientos productivos importantes con otros sectores (Ministerio de Economía de la Provincia de Buenos Aires, 2013a).

Asimismo, en 2013, el PBG de la PBA representaba el $36 \%$ del producto interno bruto nacional, generaba el $50 \%$ de la producción industrial, producía el $33 \%$ de las exportaciones nacionales, contribuía con el 36,8 \% de la masa impositiva coparticipable y recibía solo el 19,2 \% (Ministerio de Economía de la Provincia de Buenos Aires, 2013b). Por Coparticipación Federal de Impuestos se entiende al "sistema de transferencia de recursos fiscales entre las distintas jurisdicciones del Estado", donde existen "transferencias devolutivas", cuyo fundamento es la devolución de impuestos, que se entienden generados originalmente en cada jurisdicción, pero cuya administración fue otorgada a la Nación y "transferencias "compensatorias" que son aquellas que pretenden equipar las asimetrías de desarrollo existentes entre las jurisdicciones (Barbeito, Goldberg\& Lo Vuolo, 2004).

En materia ambiental, los problemas que afectan a la PBA incluyen la creciente generación de residuos y efluentes que contaminan el agua superficial y subterránea, sumado a la ausencia de infraestructura sanitaria en una parte relevante del territorio que ocasiona el uso de alternativas menos eficientes; inundaciones con origen antrópico por la impermeabilización de los suelos por urbanizaciones, remoción de la cobertura vegetal, etc.; por causas naturales como el incremento de las precipitaciones; entre otros. 
El artículo tiene la siguiente estructura, luego de la presente introducción, primero, se explica la metodología utilizada; segundo, se presenta la evolución del gasto público ambiental provincial en donde se considera la clasificación que adopta la PBA y luego se amplía otros rubros; tercero, se caracteriza a los actores estatales que ejecutaron el gasto y el tipo el tipo de programas financiados y por último, se presentan algunas conclusiones preliminares.

\section{Metodología}

El desarrollo del trabajo demandó considerar la información presupuestaria producida por la Contaduría General de la PBA (2014) dependiente del Ministerio de Economía. En la PBA, cabe señalar que la administración pública no financiera se encuentra integrada por la administración central (que incluye los poderes constitucionales ejecutivo, legislativo y judicial), los organismos descentralizados, los organismos no consolidados y las instituciones de seguridad social. Al igual que a nivel nacional, en la provincia se utiliza una metodología de ordenamiento de las transacciones en el presupuesto mediante clasificadores que permiten indagar en las prioridades establecidas por el gobierno para los distintos campos de política. En este trabajo se han considerado los clasificadores de gastos por finalidad y función y los combinados por finalidad y función-objeto del gasto, institucional-por finalidad y función del gasto y categoría de programas finalidad y función.

Mediante los clasificadores se accedió a la información relativa al rubro Ecología y Saneamiento Ambiental (ESA) que se encuentra dentro de los Servicios Sociales y contiene las actividades que desde la perspectiva del gobierno provincial refieren a la protección ambiental e incluyen los aspectos de ingeniería sanitaria; los sistemas de eliminación de efluentes; los residuos industriales y desechos; la contaminación del aire, agua y suelo; el control de zoonosis y vectores; la conservación de bosques naturales; y la provisión de agua potable (de alta relevancia social en una jurisdicción con una deuda social importante en materia de cobertura de los servicios y no se puede desagregar) ${ }^{2}$. En la sección 3.1 se presenta la evolución del rubro ESA desde 1997, (previo a lo cual el gasto ambiental formaba parte del gasto en salud) deflactadas por el Índice de Productos Implícitos (IPI).

En Argentina, a partir del 2007, es importante señalar que se produjo la intervención política del Instituto Nacional de Estadísticas y Censos (INDEC), situación que posteriormente dio margen para la manipulación del Índice de Precios al Consumidor del Gran Buenos Aires (IPC-GBA) y la posterior pérdida de confiabilidad en las estadísticas públicas. La manipulación del IPC afecta directamente a la estimación del producto interno bruto (PIB) y del PBG a precios corrientes (ya que interviene en el cálculo del producto en ciertos sectores) y a precios constantes (dado que impacta sobre el deflactador del IPI) (Campos, Fernández, González, Marongiu, ySacavini, 2008).

\footnotetext{
${ }^{2}$ En el presupuesto 2011 se modificó la categoría Ecología y saneamiento ambiental y pasó a llamarse Ecología y agua potable.
}

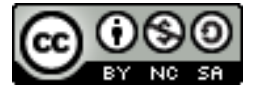


La pérdida de representatividad del IPC y la manipulación de otros indicadores públicos si bien obstaculiza la realización de estudios sobre el funcionamiento actual de los distintos sectores de la economía, más allá de estas consideraciones, las estimaciones presentadas se efectúan con las estadísticas oficiales que son las disponibles ${ }^{3}$.

De acuerdo con la literatura especializada una de las dificultades metodológicas principales en la medición del gasto ambiental es el encubrimiento del mismo dentro de otros rubros (Quadri de la Torre, 2002). Esta situación se presenta en la jurisdicción bajo análisis, especialmente, si solo se considera el rubro ESA. Para otros gastos ambientales no incluidos en dicho rubro se recurrió a la CAPA en primera instancia.

Cabe señalar que la CAPA es una clasificación funcional genérica que permite niveles de desagregación y usos múltiples utilizados para catalogar distintas actividades, productos, desembolsos $u$ otras transacciones. La CAPA aplica el criterio de objetivo final para establecer las actividades que apuntan, estrictamente, a la protección ambiental (sea de prevención, reparación o eliminación de la contaminación o degradación del aire, agua, suelos, biodiversidad, etc. (la tabla 1 del apéndice presenta los dígitos y características de las actividades según dicha metodología).

Asimismo, en segunda instancia, al gasto considerado de acuerdo con la CAPA se adicionó el gasto en obras de provisión de agua y a dicho gasto se denominó Gasto Ambiental Extendido (GAE). La decisión de incluir el gasto de obras de provisión de agua obedece a dos motivos centrales, el primero, en algunas partidas no es posible diferenciar el gasto en obras de provisión de agua con respecto al de saneamiento; y en segundo, entendemos que agua y saneamiento refieren a servicios públicos complementarios que requieren expandirse en forma conjunta dado que actúan como un sistema. Por consiguiente, son servicios con externalidades positivas no solo en materia de salud y calidad de vida de la población, sino del ambiente, fundamentalmente de los recursos hídricos y los suelos. En la sección 3.2 se presenta la evolución del GAE en términos del PBG, del gasto público total y per cápita.

Las estimaciones presentadas son de mínima en tanto no consideran algunos rubros que tienen actividades ambientales que no se han podido desagregar al interior de la estructura provincial.

Por último, en la sección 4 se identifica a los actores que ejecutaron el GAE solo para el periodo 2003-2012 por la imposibilidad de acceder a algunas fuentes y en la 5 el tipo de programas financiados en el 2010.

\footnotetext{
${ }^{3}$ En enero de 2013 se presentó un nuevo IPC a partir de distintos intercambios con representantes del Fondo Monetario Internacional (FMI).
} 


\section{El gasto público ambiental de la provincia de Buenos Aires}

\section{La evolución del gasto en Ecología y Saneamiento Ambiental.}

El periodo bajo análisis encuentra a la PBA en dos momentos de política económica nacional diferenciado que impactaron, entre otras cosas, en la administración del gasto público provincial, por un lado, durante el régimen de convertibilidad (1997-2001), con los gobiernos justicialistas de Eduardo Duhalde y Carlos Ruckauf, y por otro, luego de la devaluación, en la posconvertibilidad (2002-2012), con los gobiernos justicialistas de Felipe Solá y Daniel Scioli.

La convertibilidad de la moneda argentina respecto al dólar estadounidense, se acordó en \$1 = USD 1 , mediante la Ley de Convertibilidad N. ${ }^{\circ} 23.928$, en marzo de 1991, y se extendió hasta enero de 2002, tras la sanción de la Ley de Emergencia Pública y Reforma del Régimen Cambiario N ${ }^{\circ} 25.561$. Posteriormente, el tipo de cambio se mantuvo, hasta fines de 2011, en \$ $4=$ USD1 (con fluctuaciones) y en diciembre de 2012 finalizó \$ 4,82 = USD 1.

Por la importancia de la PBA en la producción de riqueza, las fluctuaciones en el ciclo económico nacional adquieren especial relevancia. En 1998 se inició un ciclo recesivo que implicó una importante contracción del nivel de actividad que tuvo su punto más crítico en 2002, con una caída de 11,64 \% del PBG, como se observa en la figura 1. Dicha caída impacto en las arcas fiscales de la provincia (y de los otros niveles de gobierno), en medio de un contexto altamente inflacionario producto de la devaluación de la moneda en la que el gobierno bonaerense enfrentó la situación con un proceso de ajuste centrado en los salarios del sector público, situación que repercutió en el gasto público total (Narodowski \& Panigo, 2010).

Entre 2003 y 2012 se inició uno de los ciclos de crecimiento económico más importante de la historia provincial con un ritmo anual de 8,6 \% (frente al crecimiento del 7,6 \% a nivel nacional). La recuperación se sustentó en la mejora de las actividades de mayor incidencia en el PBG: los servicios y comercio, la industria manufacturera y la construcción que contó con un fuerte impulso de la inversión pública.

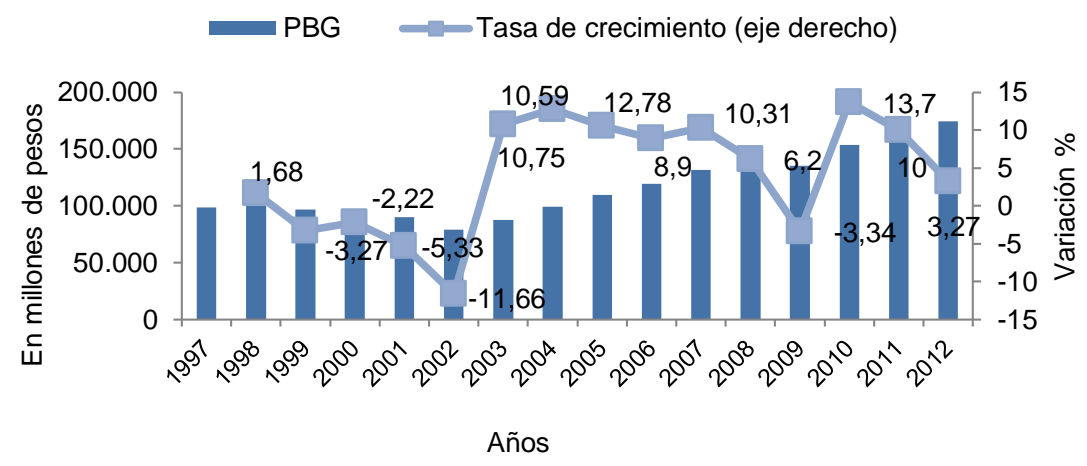

Figura 1. PBG de la PBA 1997-2012 (a precios constantes base =1993). Fuente: elaboración propia con base en la información de la Contaduría General de la PBA (2014).

Verónica L. Cáceres

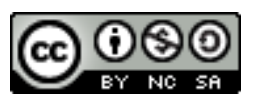

Esta obra está bajo licencia 
Tanto en la etapa de convertibilidad como en la posconvertibilidad, el gasto público provincial afrontó importantes erogaciones destinadas a cubrir el gasto primario respectivo a sueldos y educación, en tanto la PBA cuenta con 390.000 empleados públicos de los cuales el $80 \%$ son de planta permanente y el $40 \%$ son docentes (Banco Mundial, 2012). Esta situación repercutió en la rigidez del gasto a la baja que aún en la etapa recesiva de la convertibilidad creció un 5,75 $\%$, se redujo en 2002, y luego mantuvo la senda creciente, incluso con la desaceleración del crecimiento económico de 2009, en el cual experimentó una importante reducción en 2011, como presenta la figura 2. De acuerdo con Narodowski \& Panigo (2010), el gasto público en la posconvertibidad pasó a ser impulsado, a partir de 2005, por la mejora de los salarios públicos y el incremento de la planta de personal y creció un 16,11\%.

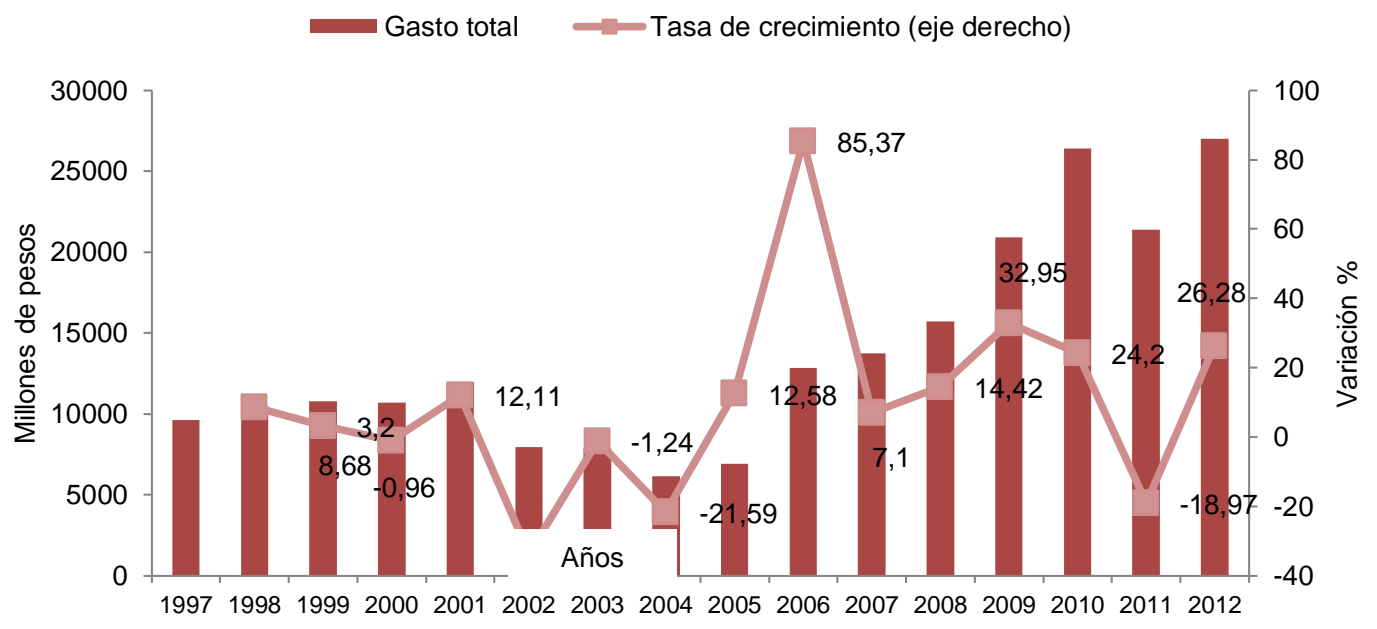

Figura 2. Evolución del gasto público total (a precios constantes base $=1993$ ). Fuente: elaboración propia con base en la información de la Contaduría General de la PBA (2014).

La figura 3 permite considerar que la relación gasto público/PBG mantiene una senda de crecimiento hasta el 2001, presenta una caída en 2002, los niveles previos a la crisis fueron superados en 2009 , cuando alcanzó el 15,49 \%. 


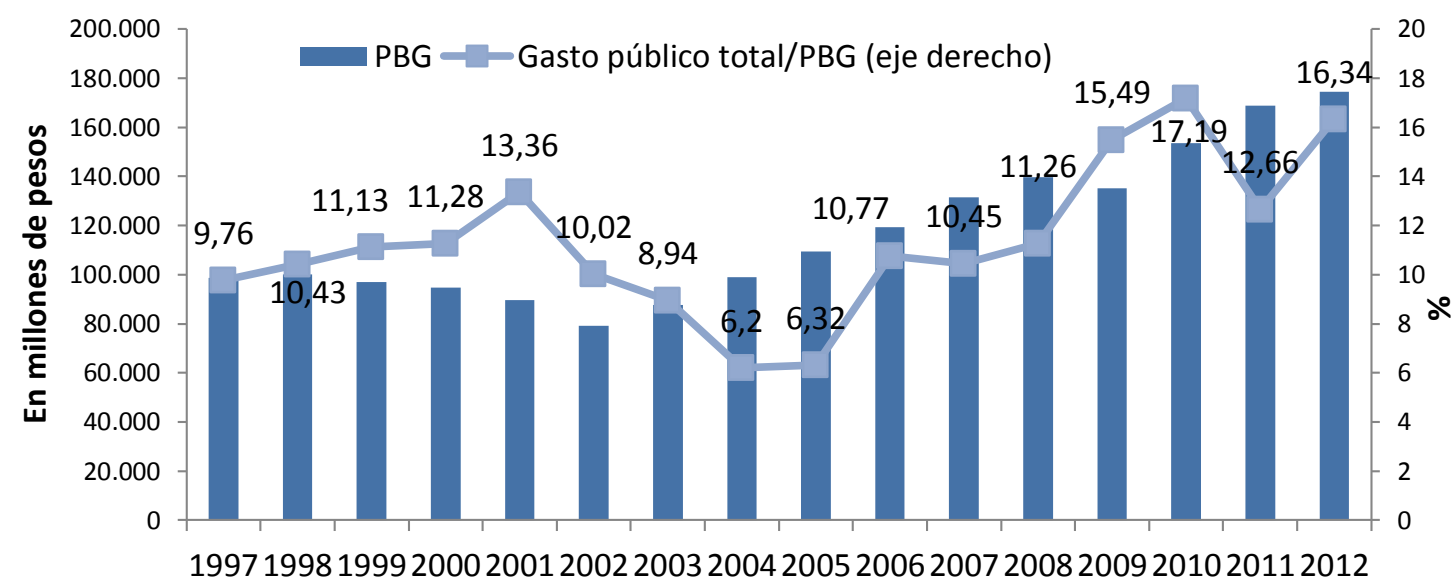

Años

Figura 3. PBG de la PBA 1997-2012 (a precios constantes base =1993). Fuente: elaboración propia con base en la información de la Contaduría General de la PBA (2014).

Aunque la participación de cada una de las finalidades en el gasto público total de la provincia difiere, con distinta intensidad, se caracteriza por la participación creciente de los Servicios Sociales que, salvo el 2001, superó ampliamente el 50 \% como permite observar la figura 4.

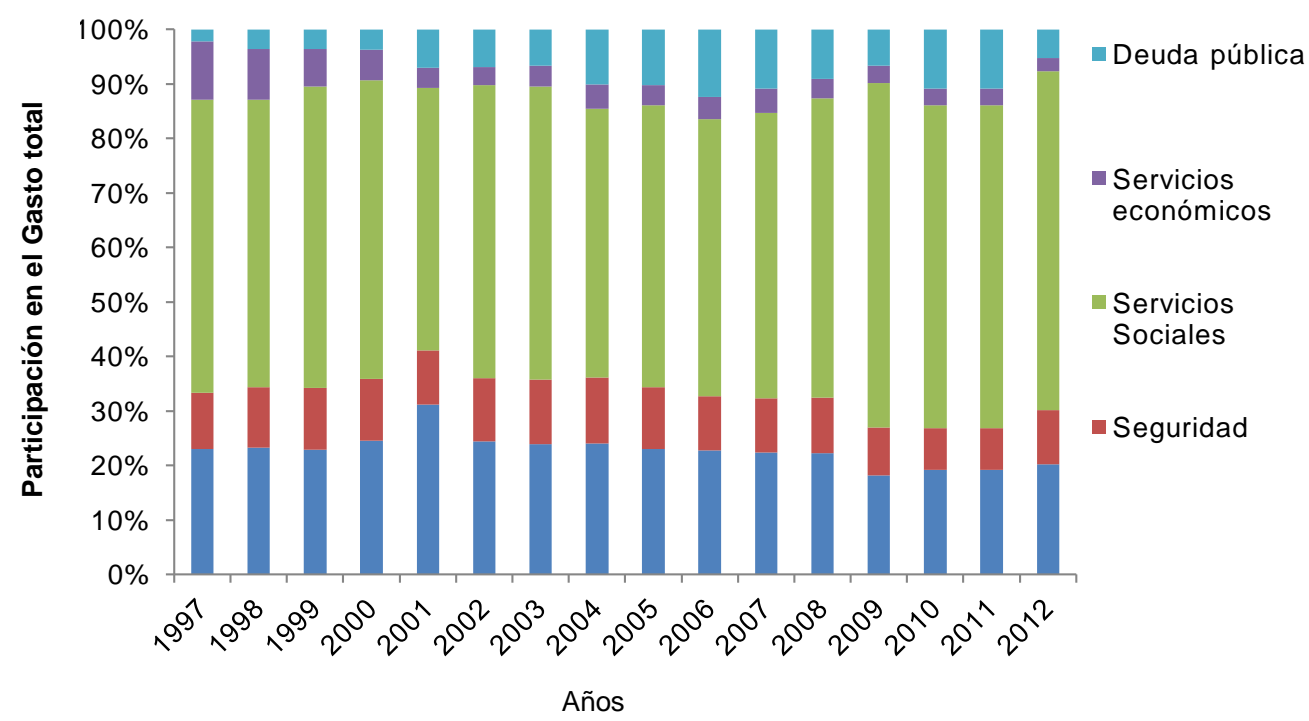

Figura 4. Estructura porcentual del Gasto público total de la Administración General (1997-2012). Fuente: elaboración propia con base en la información de la Contaduría General de la PBA (2014). 
La participación creciente del gasto destinado a Servicios Sociales se vincula de forma estrecha con la amplitud de las funciones o rubros que atiende e incluyen a Educación y Cultura; Ciencia y Técnica; Salud; Promoción y Asistencia Social; Seguridad Social; Asuntos laborales; Vivienda y Urbanismo; ESA y Deportes y Recreación. La figura 5 permite observar la evolución de las erogaciones destinadas a cada una de las finalidades y la figura 6 , la participación promedio de cada una al interior de los Servicios Sociales. En ambos se observa la relevancia que adquiere el gasto en Educación y Cultura que, en promedio, demandó el 63,41 \% del gasto público total, seguido por el gasto en Salud que requirió el15,46 \% y el gasto en Promoción y Asistencia Social que demandó el 8,57 \%. Mientras el gasto destinado a ESA ocupó solo el 2,29 \%.

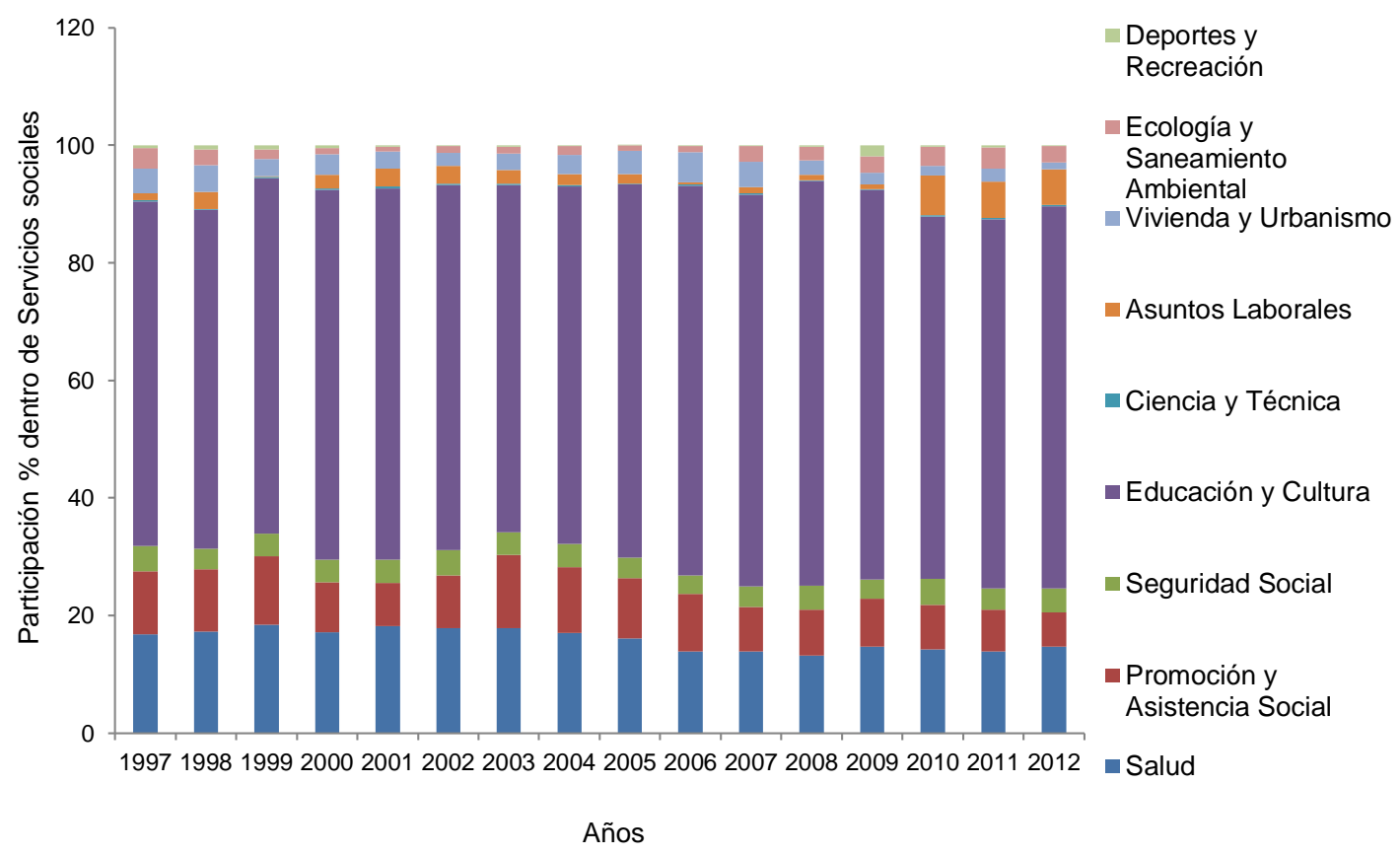

Figura 5. Participación de las distintas funciones en servicios sociales (1997-2012). Fuente: elaboración propia con base en la información de la Contaduría General de la PBA (2014). 

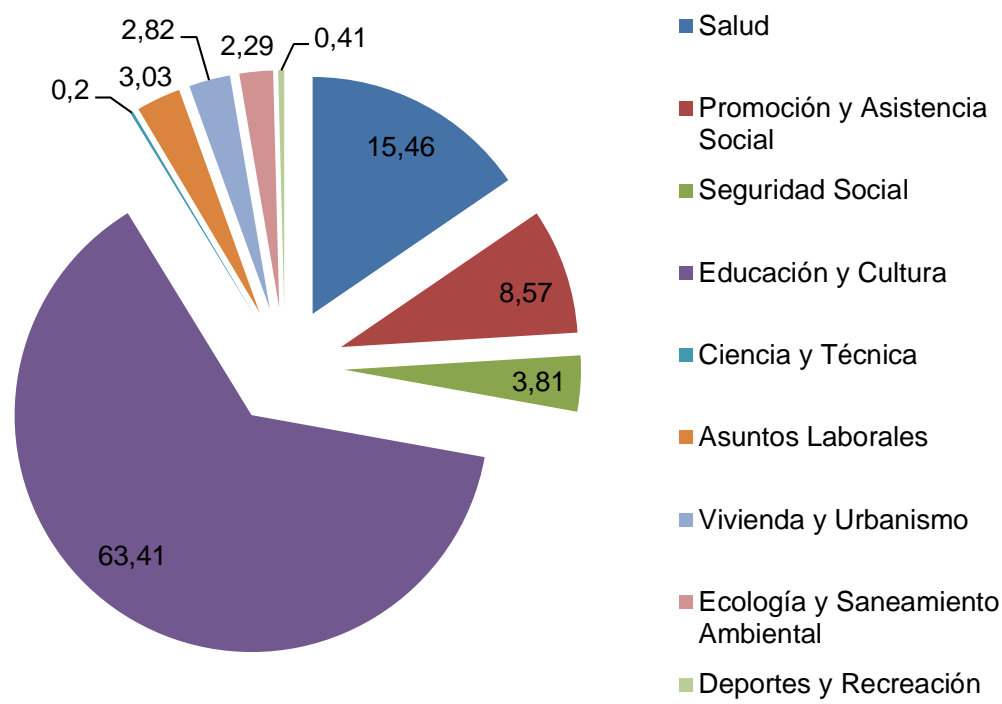

- Deportes y Recreación

Figura 6. Participación promedio de las funciones dentro de servicios sociales. Fuente: elaboración propia con base en la información de la Contaduría General de la PBA (2014).

La figura 7 permite señalar que mientras, en términos absolutos, en 1997 ESA recibía 179,85 millones de pesos constantes, en 1999 se redujo a 97,37 y los dos años siguientes continuó su caída. En 2004, el gobierno provincial destinó 74,76 millones de pesos constantes, que implicó una mejora del 53,5 \% respecto a 2003, y en 2007 se observa su pico de crecimiento. En todo el periodo el gasto acumuló 2.683,95 millones de pesos constantes.

El crecimiento del gasto público ambiental se relacionó de forma directa con el acceso y ampliación de la PBA de un crédito internacional otorgado por el Banco Internacional de Reconstrucción y Fomento (BIRF) denominado Programa de Desarrollo de la Inversión Sustentable de Infraestructura de la Provincia de Buenos Aires que incluyó los préstamos ALP-BIRF 7268 AR, ALP1 (Ampliación)- BIRF 7268 AR y ALP2-BIRF 7472 AR que alcanzó USD 514 millones.El objetivo específico del programa implementado para elperíodo 2005-2012 apunta a mejorar el bienestar social y ambiental de aproximadamente 5.000 .000 personas, especialmente para los segmentos de bajos ingresos que viven en zonas vulnerables del Conurbano Bonaerense, a partir del desarrollo de infraestructura de carreteras, agua y saneamiento, drenaje, ingeniería y estudios, competitividad y creación de empleos y desarrollo de capacidades institucionales (Banco Internacional de Reconstrucción y Fomento/Banco Mundial, 2012). 


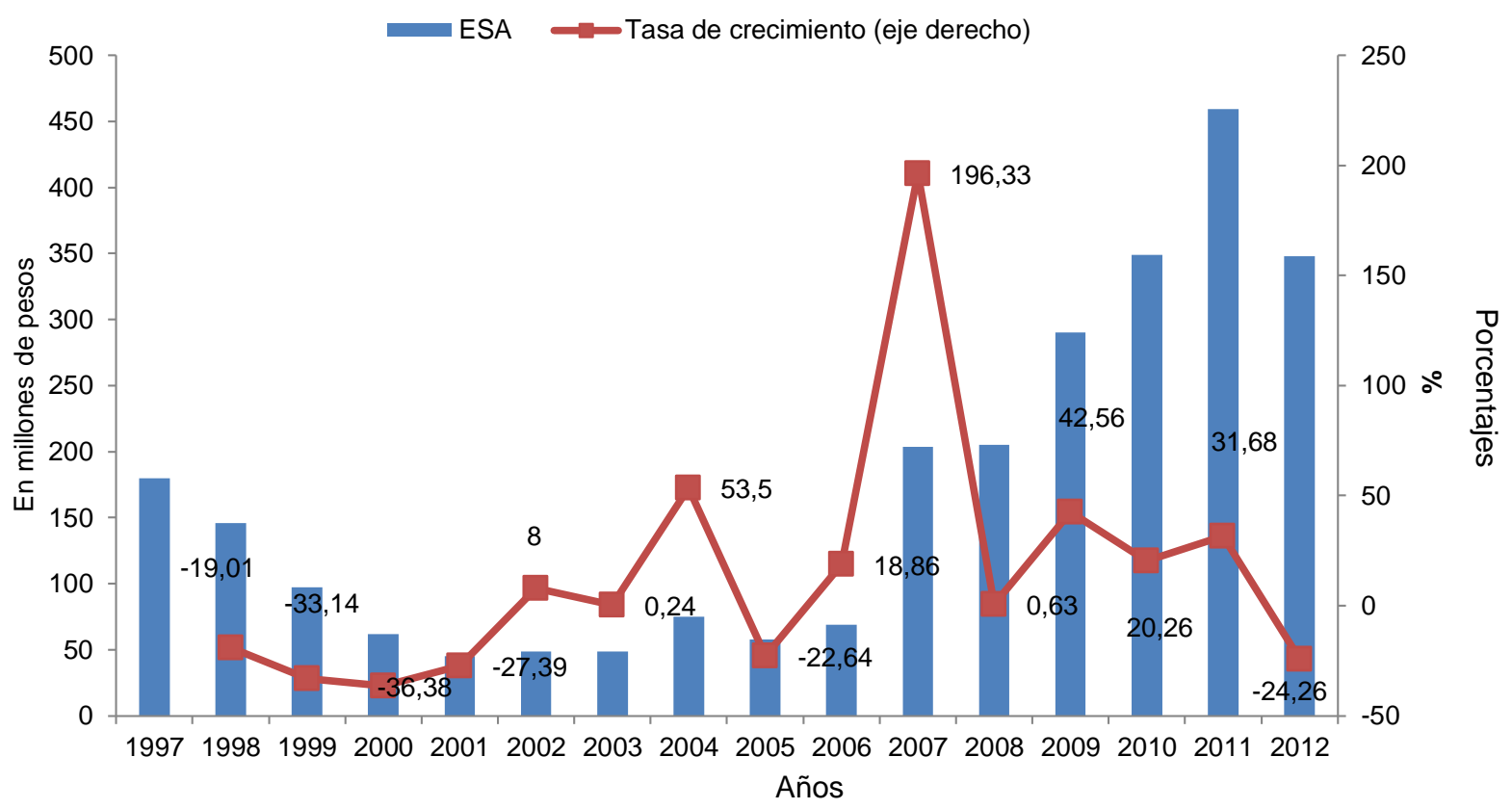

Figura 7. Evolución de Ecología y Saneamiento Ambiental (pesos constantes). Fuente: elaboración propia con base en la información de la Contaduría General de la PBA (2014).

\section{El Gasto Ambiental Extendido}

El análisis de la evolución del GAE permite observar que experimentó una caída del 15,07 \% durante el periodo recesivo, por debajo de la que experimento ESA, en tanto las actividades vinculadas al manejo de los suelos, la erosión y las inundaciones, consideradas dentro de la metodología CAPA, mantuvieron un crecimiento sostenido hasta el año 2000; y en cambio desde 2004 se observa que una proporción relevante del gasto pasó a estar destinado a obras de provisión de agua y saneamiento. La figura 8 presenta la evolución del GAE que, en términos absolutos, pasó de los 237,71 millones de pesos constantes en 1997 a los 393,7 en 2012, al acumular un total de 3.448,99 para todo el periodo. Es decir, presenta un incremento del $128,50 \%$ respecto a si solo se considera el gasto en ESA. 
GAE $\quad-$ Tasa de crecimiento del GAE (eje derecho)

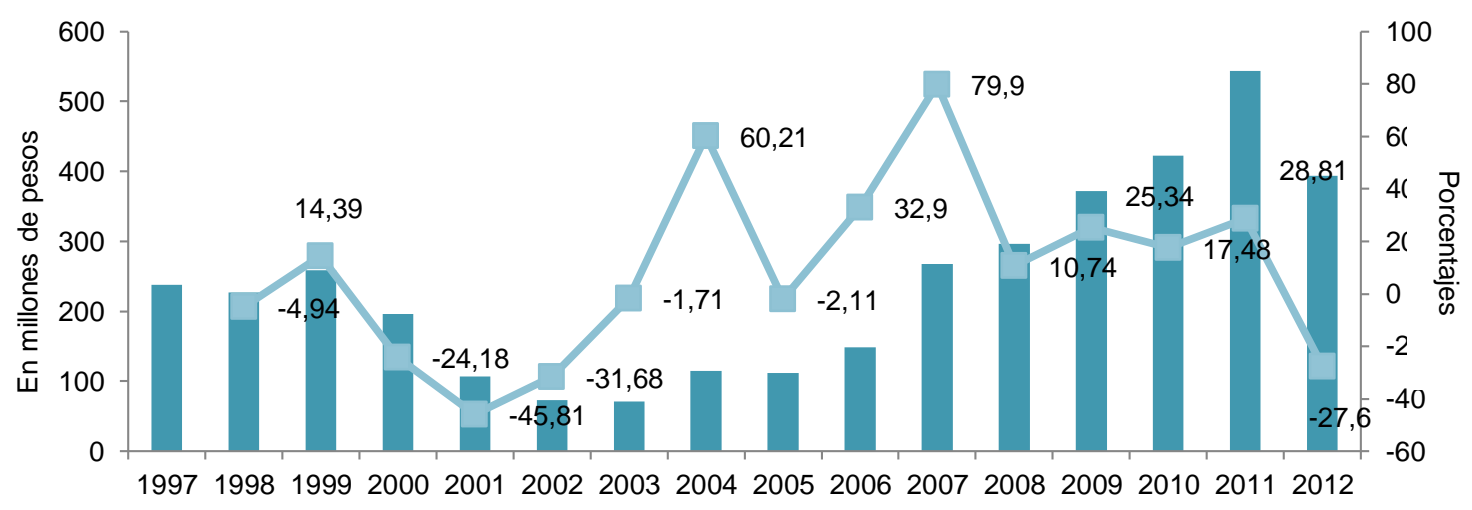

Años

Figura 8. Tasa de crecimiento del GAE (1997-2012) (constantes base 1993 = 100). Fuente: elaboración propia.

Aunque en la etapa de posconvertibilidad, la figura 9 permite observar un importante crecimiento del GAE, en un marco de fuerte crecimiento económico y mejora de las variables macroeconómicas, la relación GAE/PBG se mantuvo, prácticamente, sin alternación, ya que pasó del 0,24 \% en 1997 al 0,22 \% en 2012.

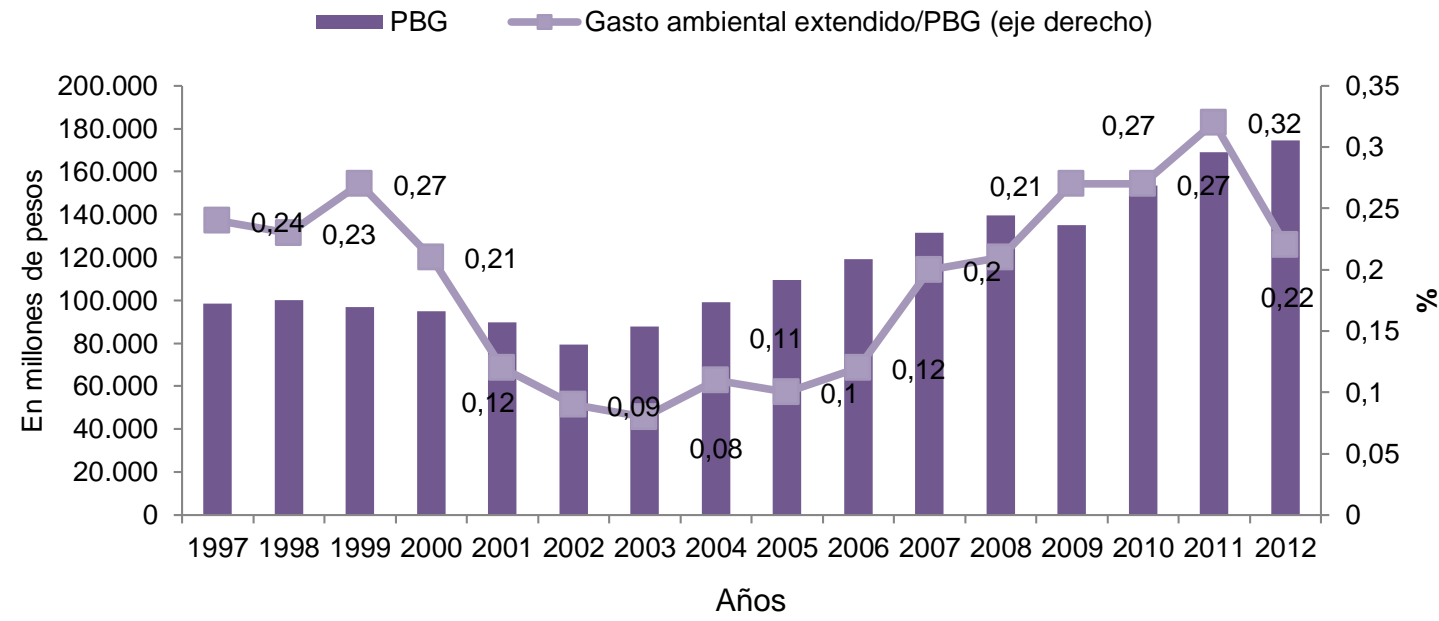

Figura 9. Evolución del GAE con respecto al PBG (1997-2012) (constantes base $1993=100)$. Fuente: elaboración propia con base en la información de la Contaduría General de la PBA (2014).

Asimismo, la figura 10 permite destacar que la relación GAE/gasto público total experimentó una caída pronunciada de $1,9 \%$ en promedio, durante el ciclo recesivo de la convertibilidad. Luego de varios años de crecimiento económico no logró alcanzar la participación de 1997,

Verónica L. Cáceres

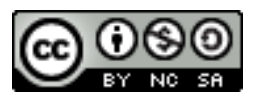

Esta obra está bajo licencia

Creative Commons Reconocimiento-NoComercial-Compartirlgual 4.0 Internacional License 
cuando el 2,47 \% del gasto público total se destinaba a actividades ambientales. Al cierre del periodo de análisis la provincia experimentaba una nueva desaceleración del crecimiento económico relevante en la que, como en otros momentos de desaceleración, se observa una caída de más de un punto porcentual de la participación del GAE/gasto público total.

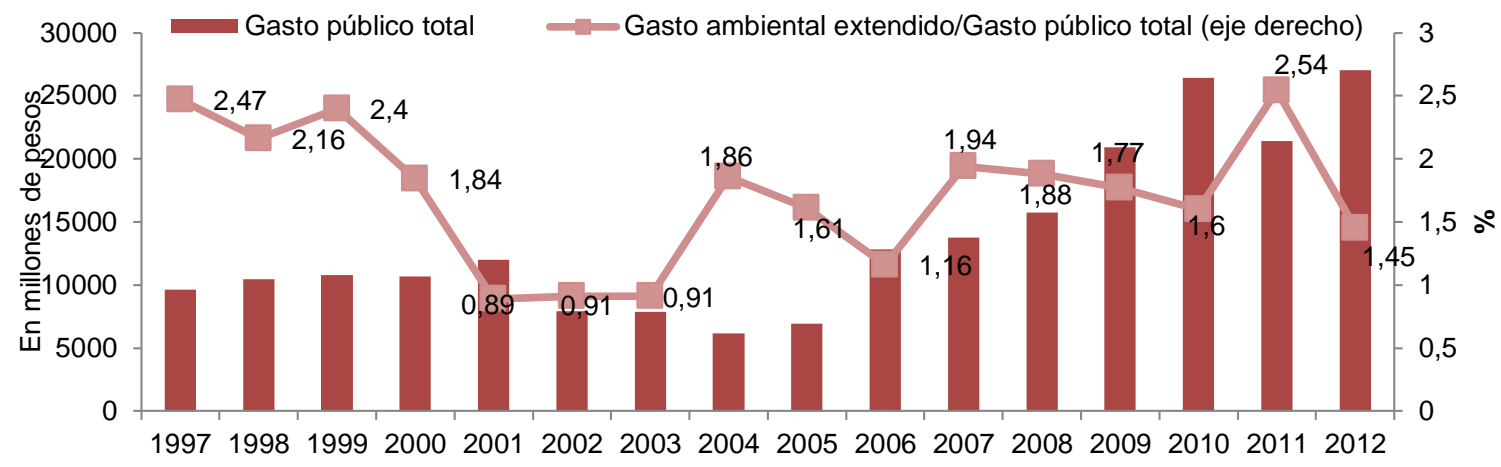

Figura 10. Evolución del GAE respecto al gasto $\mathrm{f}$ Años al (1997-2012). Fuente: elaboración propia con base en la información de la Contaduría General de la PBA (2014).

Por último, la figura 11 permite observar que el gobierno provincial pasó de destinar 17,43 pesos por habitante en 1997 en materia ambiental a 24,45 en 2012.

El recorrido realizado nos permite plantear que contrariamente a lo que sucede en otros rubros, especialmente al interior de los Servicios Sociales, el GAE fluctúa y recibe ajustes en virtud de las necesidades financieras de la PBA.

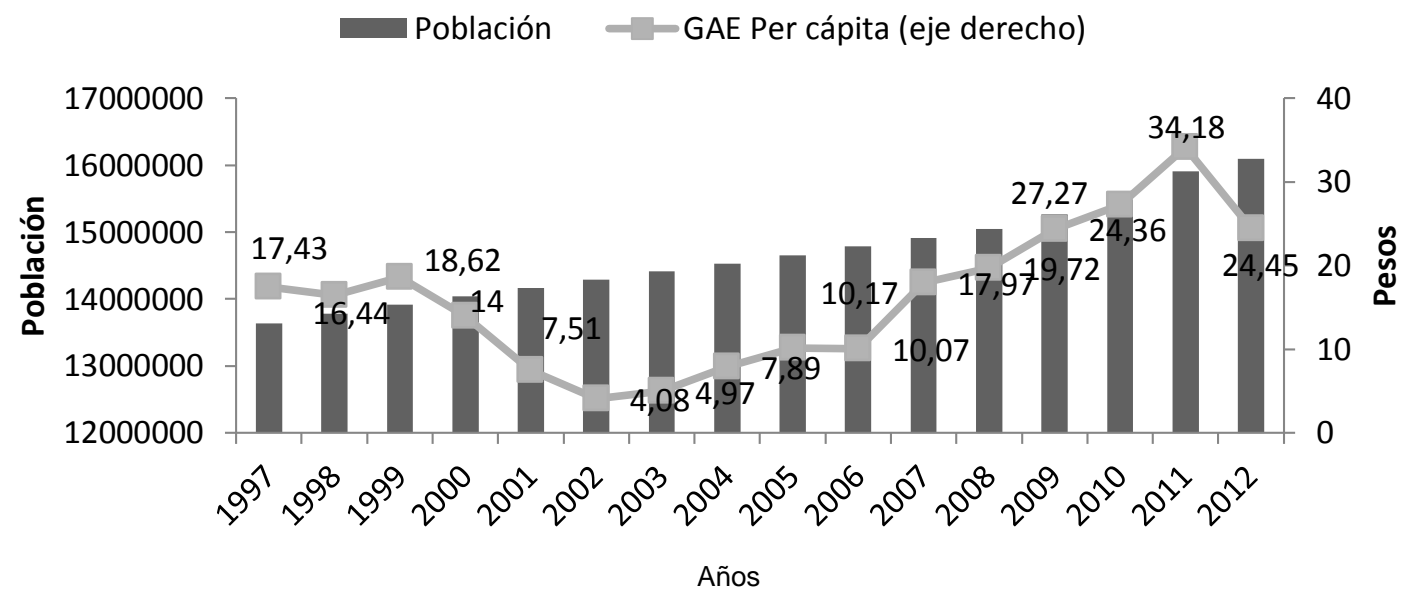

Figura 11. Evolución de Gasto Ambiental Extendido en términos per cápita (constantes base $1993=100$ ). Fuente: elaboración propia con base en la información de la Contaduría General de la PBA (2014). 


\section{Los actores que ejecutan el gasto público ambiental}

Cabe destacar que la institucionalidad ambiental en la PBA, aunque comenzó a desarrollarse desde mediados de la década de los setenta, los principales sucesos que le han impreso su sesgo actual se observan en la década del noventa, por un lado con la sanción de la primera Ley del Ambiente y la incorporación de la temática a la Constitución Provincial; y por otro con la creación de organismos específicos para atender la cuestión (Isuani, 2013).

Durante varios años la problemática ambiental estuvo vinculada al campo sanitario, de hecho la Dirección de Medio Ambiente (DMA), creada en 1991, dependió del Ministerio de Salud, y aunque la ley que dio lugar al Instituto Provincial del Ambiente (IPA) de 1993 (que reemplazó a la DMA) acordó la creación de una Cuenta Especial denominada "Fondo para el Financiamiento de Programas Ecológicos", el gasto público ambiental quedó subsumido en el gasto en salud hasta 1997.

Al IPA le sucedió en 1995 la Secretaría de Política Ambiental (SPA), dependiente de la Gobernación, que fue transformada en 2007 en el Organismo Provincial de Desarrollo Sustentable (OPDS) y ambas compartieron funciones ambientales con organismos centralizados y descentralizados que atendieron distintas aristas de la cuestión ambiental. Más allá de lo cual, la ejecución del gasto público ambiental se caracteriza por la presencia de dos tipos de actores: por un lado, aquellos que desde su constitución cumplen funciones ambientales directas en lo que concierne a la prevención, reducción, restauración, protección y conservación, mayormente, incluyen entidades con personalidad jurídica y patrimonio propio, como la OPDS; y por otro, aquellos organismos que dependen de la administración central y efectúan actividades ambientales de forma complementaria, principalmente, vinculadas con el desarrollo de obras de infraestructura, como el Ministerio de Infraestructura (MI). Estas últimas agencias han experimentado importantes cambios en su estructura y funciones durante el periodo de análisis que repercutieron en el gasto que ejecutan, la tabla 1 distingue las funciones de cada uno de los organismos, y la tabla 2 permite observar, por ejemplo que el Ministerio de Asuntos Agrarios (MAA) y la Gobernación (GOB) dejaron de ejecutar gasto público ambiental en 2007, en coincidencia con la redefinición de sus funciones por la sanción de una nueva ley de ministerios.

Tabla 1.

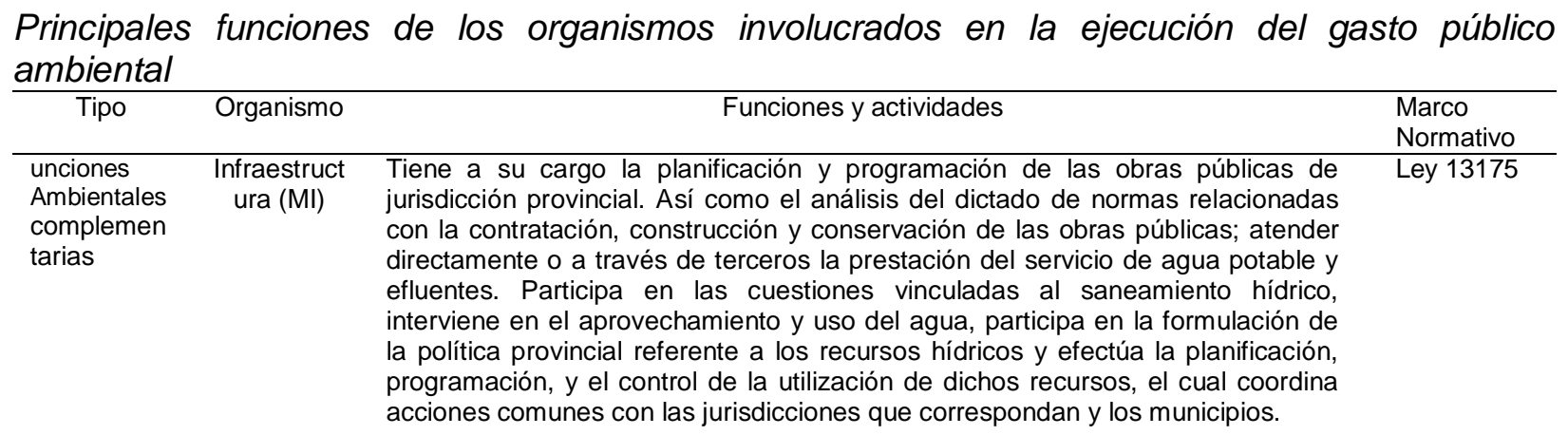

Verónica L. Cáceres

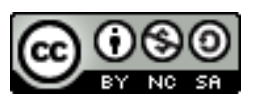

Esta obra está bajo licencia

Creative Commons Reconocimiento-NoComercial-Compartirlgual 4.0 Internacional License 
Ministerio Le compete la determinación de políticas conducentes al ordenamiento, de Asuntos promoción y desarrollo de todas las actividades agropecuarias, pesqueras y de Agrarios (MAA)

Jefatura de Gabinete (JG) producción y contralor de alimentos. Propone las políticas que favorezcan el sector y realiza la fiscalización sanitaria y el control de calidad; fiscaliza los regímenes que promueven y regulen las actividades de los sectores agropecuario, forestal y de caza; etc.

Lleva adelante la coordinación de la relación entre las distintas reparticiones ministeriales, secretarías y organismos de la administración provincial, centralizada y descentralizada; propone la creación de Comisiones interministeriales o de cualquier nivel de integración, que hagan a la mejor ejecución y coordinación de los planes, programas y proyectos emanados del Poder Ejecutivo. Interviene en la obtención directa o indirecta, en la negociación y ejecución de todos los fondos provistos por organismos multilaterales de crédito o en virtud de convenios bilaterales, etc.

\section{Funciones} ambientales directas

\section{Secretaria de política ambiental (SPA)/ \\ Organismo \\ Provincial de \\ Desarrollo \\ Sostenible (OPDS)}

Autoridad del agua

(ADA)

Organismo

de Control

de Aguas

de Buenos

Aires

(OCABA)

Servicio

Provincial

de Agua

Potable y

Saneamient

o Rural

(SPAR)

Corporació

$\mathrm{n}$ de

Fomento

del Valle

Bonaerense

del Río

Colorado

(CORFO)
Entre sus funciones se encuentran el planificar, formular, proyectar, fiscalizar, ejecutar la política ambiental, y preservar los recursos naturales; ejercer el poder de policía, establecer y fiscalizar el cumplimiento de la política sobre contaminación industrial, sus efluentes y del ambiente en general; intervenir en la conservación, protección y recuperación de reservas, áreas protegidas, y bosques, del uso racional y recuperación de suelos; la promoción de actividades vinculadas con la educación ambiental y con los estudios de impacto ambiental, entre otras.

Lleva adelante la planificación hidrológica, la reglamentación, supervisión y vigilancia de todas las actividades y obras relativas al estudio, captación, uso, conservación y evacuación del agua. La promoción de programas de educación formal e informal sobre el uso racional del agua, etc.

Tiene a su cargo el control y fiscalización de la prestación del servicio público de agua y cloacas en todo el ámbito de la Provincia de Buenos Aires, así como la defensa de los intereses de los usuarios, la intervención en las cuestiones relacionadas con la actividad de las prestatarias del servicio; velar por la protección del medio ambiente, etc.

Entre sus funciones se encuentran poder solicitar al prestador bajo su órbita la información necesaria que permita la fiscalización de los servicios que presta y opera, se considera específicamente aquellos aspectos económicos, técnicos, jurídicos y sociales; cumplir con el programa de control del servicio elaborado por el OCABA que atiende las características de cada prestador a fiscalizar; realizar los muestreos y análisis encomendados por el OCABA en los tiempos previstos por este; evaluar la información del prestador y elevar los informes al OCABA.

Administra el servicio de riego del río Colorado en los partidos de Villarino y Patagones. Específicamente tiene capacidad jurídica para realizar la planificación integral de la zona, celebrar convenios ad referendum del Poder Ejecutivo, con entidades similares que se constituyan en otras provincias, a los fines de la formación de un ente interprovincial para la realización de obras tendientes al mejor aprovechamiento y distribución de las aguas del río Colorado, que aseguren un caudal permanente para el riego; el estudio, proyección, ejecución y explotación de las obras de canalización y desagües que permitan el mejor aprovechamiento del caudal del río Colorado, entre otras.
Leyes

13175 y

13881

Ley 13757

Ley 13757

Decreto

23/2007

Ley 12257

Decreto

878/2003

Leyes 7533

y 7868

Decreto

2597/2006

Ley 7948

DecretoLey

9.541/1980

Ley 12257

Fuente: elaboración propia 
Tabla 2.

GAE de la PBA durante 2003-2012 (Estructura porcentual)

\begin{tabular}{ccccccccccc}
\hline Repartición & 2003 & 2004 & 2005 & 2006 & 2007 & 2008 & 2009 & 2010 & 2011 & 2012 \\
OTCM & 50,61 & 25 & 24 & 17,54 & 50,80 & 39,32 & 47,53 & 51,55 & 38 & 42,57 \\
M) & 25,41 & 49 & 44 & 58,43 & 32,14 & 43,29 & 33,59 & 28,16 & 41 & 31,56 \\
MAA & 5,75 & 1 & 1 & 0,37 & 0 & 0 & 0 & 0 & 0 & 0 \\
GOB & 0 & 3 & 5 & 4,38 & 0,54 & 0 & 0 & 0 & 0 & 0 \\
JG & 0 & 0 & 0 & 0 & 0 & 0 & 0 & 0 & 3 & 0 \\
SPA)/ OPDS & 0 & 0 & 0 & 0,00 & 2,31 & 3,21 & 3,91 & 4,03 & 3 & 7,98 \\
ADA & 8,26 & 13 & 16 & 10,98 & 8,03 & 8,11 & 7,77 & 6,30 & 5 & 7,11 \\
OCABA & 1,21 & 3 & 4 & 2,58 & 1,85 & 1,78 & 1,76 & 1,45 & 1 & 1,66 \\
& & & & & & & & & & \\
SPAR & 2,28 & 0 & 2 & 2,53 & 1,84 & 1,89 & 2,93 & 5,46 & 7 & 7,26 \\
CORFO & 6,48 & 5 & 5 & 3,20 & 2,48 & 2,30 & 2,30 & 2,07 & 1 & 1,80 \\
COMIREC & 0 & 0 & 0 & 0 & 0 & 0,10 & 0,22 & 0,95 & 0 & 0,06 \\
\hline
\end{tabular}

Fuente: elaboración propia.

A la fragmentación institucional en materia ambiental presentada se le adiciona otro actor: la repartición auxiliar denominada Obligaciones del Tesoro y Créditos de Emergencia (OTCE) que actúa bajo el Ministerio de Economía, y recibe partidas de las distintas finalidades (no solo de ambiente) para brindar asistencia financiera a diferentes áreas de los sectores público y privado, atender las obligaciones emergentes de compromisos con organismos provinciales, nacionales e internacionales. A diferencia de lo que sucede con la Administración Central, Organismos Descentralizados e Instituciones de Seguridad Social, las erogaciones que tienen como fuente 0 destino de la transferencia a las OTCE pueden transferirse entre sí y sufrir movimientos de acuerdo con las coyunturas, ya que no se le aplican las limitaciones para direccionar partidas presupuestarias (presente para el resto de las reparticiones). Esta situación adquiere especial relevancia en el caso en cuestión, en tanto como permite observar la figura 12, por su participación porcentual las OTCE es la segunda repartición en ejecutar GAE, precedida por el MI.

Si bien, los dispositivos normativos otorgan a los organismos con funciones ambientales específicas un lugar estratégico en la implementación de actividades ambientales, su participación en la ejecución del gasto es mínima en relación con el resto de los organismos. En 
tanto, la SPA y la OPDS ejecutaron el $1,74 \%$; la ADA el $9,71 \%$, la CORFO y el SPAR el 2,36 $\%$; el OCABA el $2,15 \%$ y el COMIREC el $0,16 \%$.
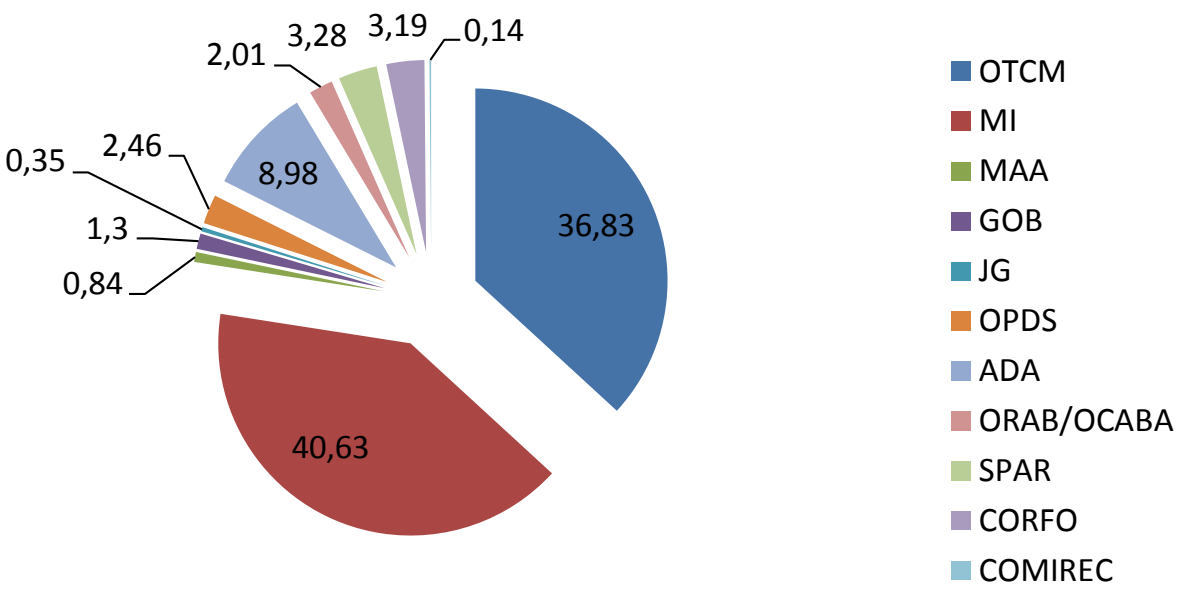

Figura 12. Participación porcentual del gasto público ambiental según institución promedio 2003-2012. Fuente: elaboración propia con base en la información de la Contaduría General de la PBA (2014).

\section{Programas ambientales}

En las secciones anteriores hemos presentado la evolución del gasto público ambiental tanto a partir de la propia clasificación provincial como en una clasificación que incorpora otros rubros. En esta sección nos interesa realizar una aproximación al tipo de programas que recibe financiamiento. La tabla 3 presenta los programas que contaron con ejecución presupuestaria en territorio bonaerense durante 2010. Los mismos están vinculados con el desarrollo de obras de provisión de agua potable y gestión de las aguas residuales, saneamiento de cursos de agua y desagües pluviales, obras de infraestructura sustentable y control de las aguas subterráneas. En concordancia con lo señalado en la sección anterior, los programas más importantes (en términos de las erogaciones destinadas) fueron implementados por el Ml y no por las agencias con funciones ambientales específicas. 


\section{Tabla 3.}

Programas ambientales y organismos que los implementan, 2010

\begin{tabular}{|c|c|c|}
\hline Tipo & Organismo & Programas \\
\hline $\begin{array}{l}\text { Funciones } \\
\text { Ambientales } \\
\text { complementa } \\
\text { rias }\end{array}$ & $\mathrm{Ml}$ & $\begin{array}{l}\text { Obras de Fortalecimiento a Organizaciones } \\
\text { Sociales } \\
\text { Apoyo a la Inversión en Sectores Sociales } \\
\text { de la Provincia de Buenos Aires } \\
\text { Programa de Desarrollo de Investigación } \\
\text { Sustentable en Infraestructura (Aguas y } \\
\text { Cloacas) } \\
\text { Saneamiento Sanitario } \\
\text { Desarrollo de Investigación Sustentable en } \\
\text { Infraestructura de la Provincia de Buenos } \\
\text { Aires. } \\
\text { Obras Fondo Fiduciario Federal de } \\
\text { Infraestructura Regional } \\
\text { Saneamiento Hidráulico } \\
\text { Saneamiento Ambiental. Unidad de } \\
\text { Coordinación del Río Reconquista. } \\
\text { Fondo Provincial de Transporte } \\
\text { Programa de Gestión Ambiental. Autoridad } \\
\text { de Cuenca Matanza Riachuelo (ACUMAR) } \\
\text { Obras Fondo. Fiduciario Federal de } \\
\text { Infraestructura Regional }\end{array}$ \\
\hline \multirow[t]{4}{*}{$\begin{array}{l}\text { Funciones } \\
\text { ambientales } \\
\text { directas }\end{array}$} & SPA/OPDS & $\begin{array}{l}\text { Coordinación para el Desarrollo Sostenible } \\
\text { Preservación de las Áreas Naturales } \\
\text { Protegidas }\end{array}$ \\
\hline & OCABA & Regulación/Control de Agua \\
\hline & SPAR & $\begin{array}{l}\text { Agua Potable } \\
\text { Desagües Cloacales } \\
\text { Programa de Agua Potable y Saneamiento } \\
\text { para Comunidades Menores }\end{array}$ \\
\hline & COMIREC & $\begin{array}{l}\text { Coordinación de la CORFO. } \\
\text { Operar y mantenimiento de Máquinas } \\
\text { Operación y mantenimiento de la Red de } \\
\text { Riego y Desagües } \\
\text { Generación y Transferencia de Tecnología } \\
\text { Comité de la Cuenca del Río Reconquista }\end{array}$ \\
\hline
\end{tabular}

Fuente: elaboración propia con base en la información de la Contaduría General de la PBA (2014). 
En la tabla anterior es sobresaliente la ausencia de programas de concientización y participación ciudadana, de promoción de una cultura sostenible con el ambiente y de inclusión de cambios en los procesos productivos. Tampoco programas ambientales en otros ámbitos como el sistema educativo (aunque existen contenidos ambientales en los currículos escolares de los distintos niveles) y en el sistema de salud, esto se vincula, desde nuestra perspectiva, al sesgo sectorial que asume el gasto público ambiental y a la poca incidencia de los organismos con funciones ambientales especificas donde existen instancias de participación de la sociedad civil.

\section{Conclusiones preliminares}

La presentación realizada a lo largo de las distintas secciones del trabajo nos permitió estimar el gasto público ambiental de la PBA, identificar a los actores que lo ejecutaron y realizar una aproximación a los programas que lo implementaron. Dicho gasto tiende a fluctuar en virtud de las necesidades financieras de la provincia, en la fase recesiva de la convertibilidad perdió una parte importante de la participación respecto al PBG y el gasto público total, que luego de una década de crecimiento económico, en la posconvertibilidad donde, si bien experimentó una mejora, no logró recuperar los niveles iníciales. La mejora se observa desde 2004 y se vincula con el acceso y reestructuración de la provincia a un crédito internacional destinado a obras de infraestructura. Asimismo, el gasto se caracteriza por una perspectiva sectorial que enfatiza en temas de agua y saneamiento; un fuerte componente de participación de las agencias centralizadas en detrimento de las que aglutinan las funciones ambientales principales; y por la escasa relevancia que tienen las actividades de promoción y educación en materia ambiental.

En primer lugar, en la etapa de convertibilidad el gasto público ambiental se encontraba más diversificado, en tanto incluía partidas importantes en actividades de protección de la erosión de los suelos y de alcantarillado, sobre todo en áreas rurales. En la posconvertibilidad, cuando el gasto comenzó a recuperarse, se observa un giro hacia la implementación de algunos programas vinculados al agua y saneamiento doméstico y de algunas cuencas hidrográficas, con énfasis en el territorio del conurbano bonaerense. El Estado provincial retomó la responsabilidad sobre la provisión de los servicios privatizados a fines de 1999 y comenzó a implementar un conjunto de obras que apuntaron a mejorar la provisión. Cabe destacar que en la PBA, para el 2010, solo el 75,09 \% de los hogares accedía al agua mediante las redes centralizadas y organizadas institucionalmente por el Estado y el 47,57 \% al servicio de cloacas. Por lo que existía una porción importante de hogares que residía, y aún lo hace, en áreas no conectadas a dichas infraestructuras, principalmente en los municipios más empobrecidos de la "periferia" del conurbano bonaerense que quedaba obligada a abastecerse de agua mediante formas menos seguras como la extracción con perforaciones y bombas; y a resolver el saneamiento a través de "pozos ciegos" en los suelos (Instituto Nacional de Estadísticas y Censos, 2010).

La falta de saneamiento adecuado (que afecta a más de la mitad de los hogares) y los bajos niveles de tratamiento de los efluentes domésticos recolectados por las empresas prestatarias de los servicios han generado graves problemas de contaminación de algunas cuencas

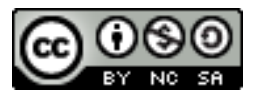

Esta obra está bajo licencia 
hidrográficas (a lo que se suma la contaminación industrial de los emprendimientos instalados en las riberas). En la posconvertibilidad, la provincia (junto al Estado nacional y a la ciudad de Buenos Aires) ha sido condenada por la contaminación de la cuenca Matanza-Riachuelo, donde se asienta el polo industrial desde mediados del siglo pasado, y las tres jurisdicciones con competencias están obligadas por la justicia a implementar programas de saneamiento ambiental integral en la misma. En el caso de la PBA dichos programas se encuentran a cargo de las agencias con funciones ambientales complementarias.

En segundo lugar, cabe destacar que aunque la PBA cuenta con un proceso de institucionalización de la cuestión ambiental de larga data y con un conjunto fragmentado de agencias autárquicas que cumplen las principales funciones ambientales, donde existen instancias de participación de la sociedad civil. Las mismas tienen un papel casi formal en la política ambiental, en tanto cuentan con escasos recursos financieros para poder implementar los programas ambientales asociados con las funciones. Por el contrario, las agencias centralizadas que cumplen funciones ambientales complementarias, al menos desde su constitución, formulan e implementan los programas más importantes. Lo cual se explicita en el hecho que acapararon cerca del $80 \%$ de las erogaciones destinadas al ambiente. La asignación del gasto público ambiental depende de las dinámicas del juego político provincial donde hay una fuerte incidencia del gobierno de turno y escasa participación de actores de la sociedad civil (universidades, centros de investigación, organizaciones de base, etc.) en la selección, por ejemplo, del tipo de obras que requieren inversiones en infraestructuras significativas y del territorio donde se llevarán a cabo. Lo cual genera que el Poder Ejecutivo Provincial mantenga amplias facultades para definir qué actividades ambientales priorizar y en qué territorios desarrollarlas.

Por último, las actividades de promoción y educación en materia ambiental, más allá de la importancia que tienen en lo que concierne al cuidado del ambiente no están presentes, en las agencias que tienen que diseñar, formular e implementar dichos programas tienen poco margen financiero para poder llevarlos adelante y las iniciativas que implementan tienen una escala reducida y no se sostienen en el tiempo.

Asimismo, preocupa la fragmentación institucional en el campo, la debilidad relativa de las agencias que cumplen las funciones ambientales principales, la nula incidencia que tienen otras actividades como ser de protección del aire y de la biodiversidad, la mitigación de ruidos y vibraciones, las acciones vinculadas al cambio climático en general, entre otras. Estas son problemas que requieren comenzar a discutirse en la agenda del Estado provincial, con el nivel nacional y otras jurisdicciones, y con la participación de otros actores no estatales, lo cual demanda complejizar el debate, aunar los esfuerzos en la asignación de recursos, etc. Sin lo cual poco se puede avanzar en la formulación e implementación de la política ambiental que logre integrar las distintas aristas de la cuestión, los graves problemas que afectan a la provincia, las distintas escalas y enfoques, que coordine de forma estratégica y que sea coherente con otras políticas que perduren más allá de la gestión de un gobierno particular. 


\section{Referencias}

Banco Mundial (2012). Province of Buenos Aires. Republic of Argentina. Public Financial Management Assessment. Recuperado de:

https://openknowledge.worldbank.org/bitstream/handle/10986/11921/724010ESW0P 12109011020120Box371916B.pdf?sequence $=1$

Barbeito, A.; Goldberg, L. \&LoVuolo, R. (2004). Notas sobre el régimen de Coparticipación Federal de Impuestos. Recuperado de:

http://www.ciepp.org.ar/index.php?page=shop.product details\&flypage=flypage new1.tp \& product id=109\&category id=9\&option=com virtuemart\&ltemid=2\&lang=es

Campos, L. Fernández A., González, M. Marongiu, F. \&Sacavini, M. (2008).La Situación de los Trabajadores en Argentina frente a la crisis económica actual. Trabajo presentado en el $9^{\circ}$ Congreso Nacional de Estudio del Trabajo en la Facultad de Ciencias Económicas, Universidad de Buenos Aires. Recuperado de: http://www.aset.org.ar/congresos/9/Ponencias/p1 Campos.pdf

Contaduría General de la Provincia de Buenos Aires. (2014).Presupuestaria Dirección General. Cierre de ejercicios anteriores. Recuperado de:

http://www.cgp.gba.gov.ar/presupuestaria/descargar-ejecucion.aspx

Isuani, F. (2013). Institucionalidad Ambiental en la Provincia de Buenos Aires (1983-2011). Desafíos a la coherencia, integralidad y coordinación. Trabajo presentado en el VII Congreso Argentino de Administración Pública "Liderazgo, Equidad y Sustentabilidad", Argentina Mendoza. Recuperado de:

http://www.ungs.edu.ar/ms ico/wp-content/uploads/2014/10/Pol\%C3\%ADticaAmbiental-en-la-Provincia-de-Buenos-Aire-Isuani-20131.pdf

Narodowski, P.\& Panigo, D. (2010). Cuadernos de Economía $N^{\circ} 75$. El nuevo modelo de desarrollo nacional y su impacto en la Provincia de Buenos Aires. Recuperado de: http://www.ec.gba.gov.ar/prensa/Archivos/Cuaderno75.pdf

Quadri de la Torre, G. (2002). Metodologías de Estimación del Gasto Ambiental. México: Instituto Nacional de Ecología. Recuperado de:

http://www.inecc.gob.mx/descargas/dgipea/gasto amb.pdf

Instituto Nacional de Estadísticas y Censos (2010). Censo Nacional de Población, Hogares y Viviendas de 2010. Censos del Bicentenario. Resultados definitivos. Serie B N². Tomo 1. Recuperado de:

http://www.censo2010.indec.gov.ar/archivos/censo2010 tomo1.pdf 
Ministerio de Economía de la Provincia de Buenos Aires (2013a). Dirección Provincial de Estadística. La provincia en cifras, Octubre de 2013. Recuperado de: http://www.ec.gba.gov.ar/areas/estudios proyecciones/presentaciones/La\%20Provincia \%20en\%20cifras\%20-\%200ctubre\%20de\%202013.pdf

Ministerio de Economía de la Provincia de Buenos Aires (2013b). Dirección Provincial de Estadística. Producto Bruto Geográfico de la provincia de Buenos Aires. Recuperado de: http://www.ec.gba.gov.ar/Estadistica/Pbg 2012 09oct13.pdf

Naciones Unidas. (2002). Contabilidad ambiental y económica integrada. Manual de operaciones. Serie F(78). Recuperado de:

https://unstats.un.org/unsd/publication/SeriesF/SeriesF 78S.pdf

\section{Apéndice}

\section{Tabla 4.}

\section{Dígitos y características de las actividades según CAPA}

\begin{tabular}{|c|c|c|}
\hline Digito & Componente & Detalle \\
\hline 1. Aire & $\begin{array}{l}\text { Protección del aire } \\
\text { y cambio climático }\end{array}$ & $\begin{array}{l}\text { La categoría incluye las acciones destinadas a reducir el impacto } \\
\text { negativo de los gases que afectan a la capa de ozono y el control } \\
\text { de otras emisiones gaseosas. Así como la promoción del uso de } \\
\text { tecnologías limpias y energías renovables. }\end{array}$ \\
\hline 2. Agua & $\begin{array}{l}\text { Gestión de aguas } \\
\text { residuales }\end{array}$ & $\begin{array}{l}\text { Consideran las acciones ligadas a la prevención de la } \\
\text { contaminación hídrica. Incluye las obras de alcantarillado, los } \\
\text { desagües pluviales y cloacales. }\end{array}$ \\
\hline 3. Suelos & $\begin{array}{l}\text { Manejo de } \\
\text { residuos } \\
\text { Protección y } \\
\text { remediación de } \\
\text { suelos, aguas } \\
\text { subterráneas }\end{array}$ & $\begin{array}{l}\text { Incluyen las acciones que apuntan al ordenamiento del manejo de } \\
\text { los residuos domiciliarios e industriales } \\
\text { Consideran las actividades destinadas al saneamiento de recursos } \\
\text { hídricos contaminados }\end{array}$ \\
\hline & $\begin{array}{c}\text { Mitigación de ruido } \\
\text { y vibraciones }\end{array}$ & Gastos asociados a la moderación del ruido. \\
\hline $\begin{array}{c}5 . \\
\text { Biodiversidad }\end{array}$ & $\begin{array}{l}\text { Protección de la } \\
\text { biodiversidad y del } \\
\text { paisaje }\end{array}$ & $\begin{array}{l}\text { Consideran las acciones de conservación, reintroducción y } \\
\text { recuperación de las especies animales y vegetales y sus hábitats } \\
\text { naturales. Así también las destinadas a la protección y } \\
\text { preservación de parques nacionales y reservas ecológicas etc., e } \\
\text { incendios forestales. }\end{array}$ \\
\hline $\begin{array}{l}6 . \\
\text { Investigación y } \\
\text { desarrollo }\end{array}$ & $\begin{array}{l}\text { Investigación y } \\
\text { desarrollo }\end{array}$ & $\begin{array}{l}\text { Actividades de investigación que efectúan las instituciones públicas } \\
\text { que apuntan a aumentar el conocimiento sobre distintos } \\
\text { segmentos del ambiente. }\end{array}$ \\
\hline
\end{tabular}




\section{Otras \\ actividades de protección ambiental}

Otras

Incorporan, por ejemplo, los gastos de conducción y gestión

implementados para el desarrollo de los programas y acciones.

Fuente: elaboración propia en base a Naciones Unidas (2002) y Quadri de la Torre (2002). 